\title{
Follow up study of labial salivary gland lesions in primary Sjögren's syndrome
}

\author{
J P Leroy, Y L Pennec, Catherine Soulier, J M Berthelot, G Letoux, P Youinou
}

\begin{abstract}
Labial salivary gland biopsy samples were taken from 27 patients with primary Sjögren's syndrome (SS), 10 with rheumatoid arthritis (RA) and secondary SS, and four normal control subjects on two occasions at intervals of more than one year. In the former group of patients, eight of the nine initially negative analyses were positive on the second sample, whereas two of the seven patients with RA and secondary SS were negative for the first sample and then positive for the second. In primary SS, the mean (SD) variation of the focus score was $1.7(2.6)$ and that of salivary duct infiltration $0.2(0.7)$. The former correlated well with the latter.
\end{abstract}

Sjögren's syndrome (SS) is an exocrinopathy of presumed autoimmune aetiology, ${ }^{1-3}$ of which the diagnosis requires the presence of at least two of the following components: xerostomia, keratoconjunctivitis sicca, and any connective tissue disease. The term primary SS applies to those patients with SS not associated with connective tissue disease.

Criteria are in the process of being validated for keratoconjunctivitis sicca, ${ }^{4}$ but the definition of xerostomia remains to be established. Several methods have been evaluated to aid in diagnosis. These include measurement of salivary flow, ${ }^{5}$ sialochemistry, ${ }^{6}$ sequential salivary scintigraphy, ${ }^{7}$ salivary gland echography, ${ }^{8}$ and sialography using liposoluble or hydrosoluble $^{10}$ contrast media. Overall, these tests have not proved to be sufficiently specific or sensitive to allow a diagnosis of xerostomia. In contrast, analysis of a labial salivary gland biopsy sample appears to be a reliable diagnostic approach to the oral component of SS. Although Daniels ${ }^{11}$ has proposed that focal sialadenitis is the only parameter necessary for defining xerostomia, a biopsy sample has limitations because some patients without a focal sialodenitis do have keratoconjunctivitis sicca or connective tissue disease, or both. To date, there have been few reports on the natural history of the disease based on longitudinal labial salivary gland biopsy.

Consequently, the aims of this study were to address the question as to whether a second labial salivary gland biopsy is of interest in patients with a negative histological result, and to examine if the exocrine gland lesions progress over time within a four year period.

Patients and methods

PATIENTS

Twenty seven patients presenting with subjective symptoms of dry mouth or dry eyes, or both, were considered for this study. They gave informed consent and two separate labial salivary gland biopsy samples were taken. The diagnosis of primary SS was established according to previously described criteria, ${ }^{12}$ but could not be histologically confirmed in nine patients. None of them met the criteria for an associated connective tissue disease. There were 24 women and three men. Their mean age was 59 years (range 46-78), and the mean duration of their disease was five years (range 1-16). None of the patients had lymphoma at the time of the biopsies, and none was treated in the interval between biopsies (mean (SD) interval 3.5 (2.6) years; range $1-16$ years). In addition, 10 patients fulfilling the American College of Rheumatology's revised criteria ${ }^{13}$ for the classification of rheumatoid arthritis (RA), and suspected of having secondary $\mathrm{SS},{ }^{14}$ also had two biopsy samples taken (mean (SD) interval $4.3(3.0)$ years; range 1-12 years). Samples were also obtained from four patients undergoing an operation for a benign or malignant tumour of the parotid or submandibular gland, and these were considered as normal control subjects (mean (SD) interval 4.3 (2.9) years; range 1-8 years)

\section{HISTOPATHOLOGICAL STUDY}

The labial salivary gland biopsy sample was taken by Daniels' technique ${ }^{11}$ in areas where the overlying mucosa appeared normal. The samples were then embedded in paraffin and sections cut through the middle of each gland. The focus score was calculated according to Greenspan $e t a l,{ }^{15}$ who defined a focus as an aggregate containing 50 or more mononuclear cells, and the focal score as the number of such aggregates in each $4 \mathrm{~mm}^{2}$ area. A particular note of the fibrosis and the ductal structures with infiltrating lymphocytes was made. Fibrosis, peri- and intralobular, was graded on a scale from 0 to 3 ( 0 absent, 1 mild, 2 moderate, and 3 severe). Ductal structures with infiltrating lymphocytes were arbitrarily evaluated on a similar scale from 0 to 2 . All material was examined independently by two histopathologists who had no knowledge of the clinical findings. The differences between the two sets of results were negligible.

\section{STATISTICS}

All the results are arithmetic means and standard deviations. Comparisons were made with the Wilcoxon signed rank test for paired data, and 
the correlations calculated using Spearman's rank correlation test.

\section{Results}

Eighteen patients with primary SS (63\%) and three with secondary SS (30\%), but also one normal subject $(25 \%)$ had at least two foci/ $4 \mathrm{~mm}^{2}$ on the initial biopsy specimen. In the former group of patients there was also fibrosis graded at least 2 on 15 specimens $(56 \%)$, and ductal structures with infiltrating lymphocytes graded at least 1 on $16(59 \%)$. Neither of these two abnormalities, nor the focal score, correlated

Table 1 Comparison of the results obtained for two separate labial salivary gland biopsy samples.

\begin{tabular}{|c|c|c|c|c|}
\hline \multirow{2}{*}{$\begin{array}{l}\text { First biopsy } \\
\text { sample: }\end{array}$} & \multirow{2}{*}{$\begin{array}{l}\text { Second biopsy } \\
\text { sample* }^{*}\end{array}$} & \multicolumn{3}{|l|}{ Number of subjects } \\
\hline & & $\begin{array}{l}\text { Primary Sjögren's } \\
\text { syndrome }(n=27)\end{array}$ & $\begin{array}{l}\text { Secondary Siögren's } \\
\text { svndrome }(n=10)\end{array}$ & $\begin{array}{l}\text { Normal control } \\
\text { subjects }(n=4)\end{array}$ \\
\hline $\begin{array}{l}+ \\
+ \\
- \\
-\end{array}$ & $\begin{array}{l}+ \\
- \\
+\end{array}$ & $\begin{array}{r}17 \\
1 \\
8 \\
1\end{array}$ & $\begin{array}{l}2 \\
1 \\
2 \\
5\end{array}$ & $\begin{array}{l}0 \\
1 \\
0 \\
3\end{array}$ \\
\hline
\end{tabular}

$(+)$ focus score $>2 ;(-)$ focus score $<2$.

Table 2 Quantitation (Mean (SD)) of the abnormalities detected on two labial salivary gland biopsy samples in 27 patients with primary Sjögren's syndrome.

\begin{tabular}{lllll}
\hline & $\begin{array}{l}\text { First biopsy } \\
\text { sample }\end{array}$ & $\begin{array}{l}\text { Second biopsy } \\
\text { sample }\end{array}$ & Significance & Variation \\
\hline Focus score* & $4 \cdot 2(4 \cdot 0)$ & $6 \cdot 1(4 \cdot 1)$ & $\mathrm{p}<0.01$ & $\begin{array}{l}1 \cdot 7(2 \cdot 6) \\
(\text { range }-3 \text { to }+10)\end{array}$ \\
Fibrosist & $1.3(0.9)$ & $1.7(0.8)$ & NS 5 & $\begin{array}{l}0.3(0.9) \\
(\text { range }-2 \text { to }+2)\end{array}$ \\
$\begin{array}{l}\text { Ducts infiltrated } \\
\text { with lymphocytes } \neq\end{array}$ & $0.7(0.8)$ & $0.9(0.9)$ & NS & $\begin{array}{l}0.2(0.7) \\
(\text { range }-1 \text { to }+2)\end{array}$ \\
\hline
\end{tabular}

"Graded according to Greenspan et al. ${ }^{15}$

tGraded on a scale from 1 to 4 .

fGraded on a scale from 1 to 3 .

(NS) not significant.

Lymphocytic infiltrates (arrows) on the first $(A)$ and the second $(B)$ labial salivary gland biopsy samples from a patient with primary Sjögren's syndrome.
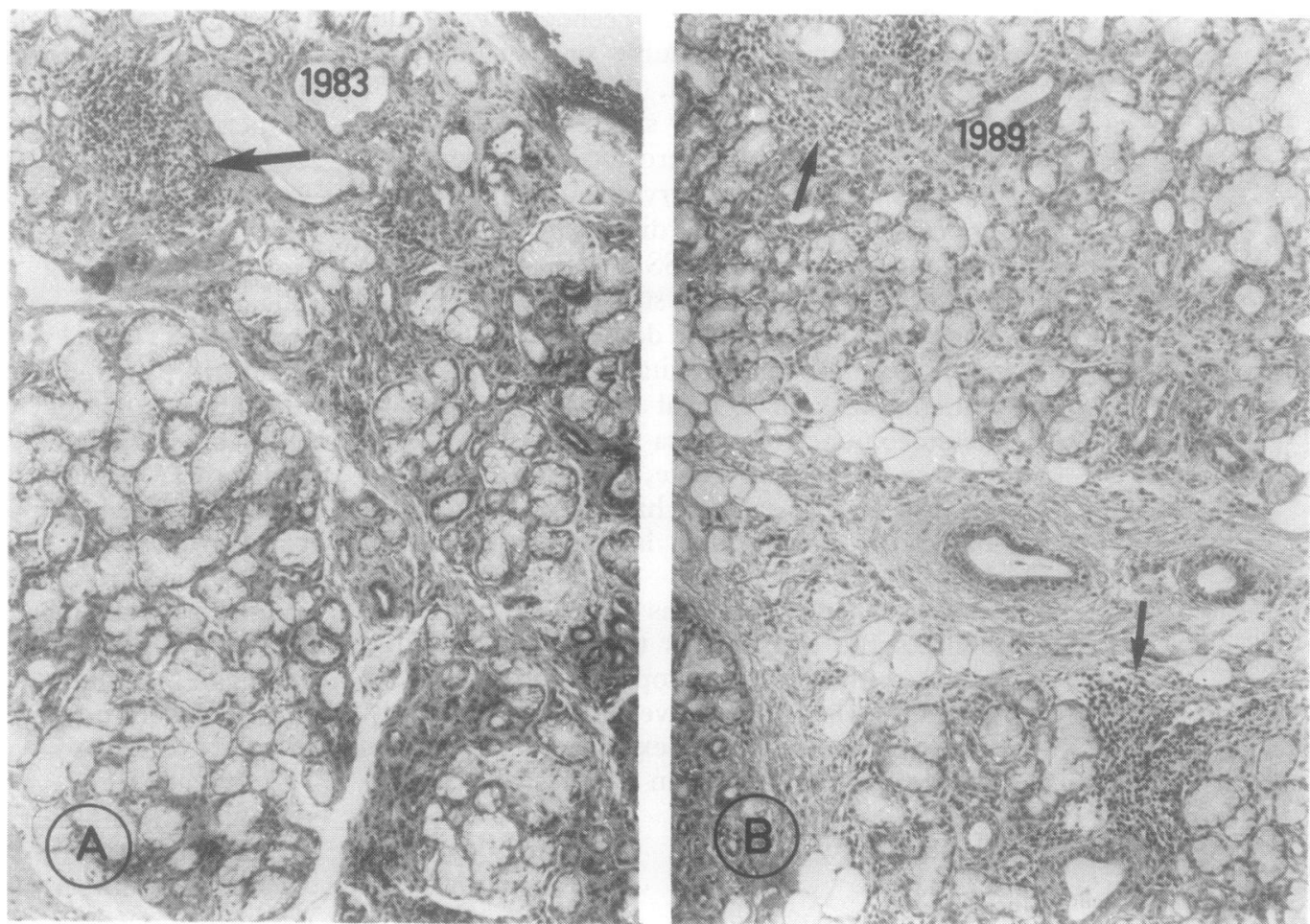

with the duration of the disease, but the focal score correlated $(p<0.04)$ with the age of the patients.

Assuming that a focal score of 2 is diagnostic for SS, it can be inferred from the data given in table 1 that eight of the nine initially negative patients with primary SS were positive on the second specimen, whereas 17 of the 18 subjects initially positive remained so after a mean interval of 3.5 years (range 1-12), and none of the three initially negative normal control subjects became positive after a mean interval of $4 \cdot 3$ years (range $1-8$ ).

In subjects with primary SS, the mean (SD) variation of the focal score $(\mathrm{V}-\mathrm{FS})$ was $1 \cdot 7(2 \cdot 6)$ (range -3 to +10$)$, evolving $(p<0 \cdot 01)$ from $4 \cdot 2$ $(4 \cdot 0)$ to $6 \cdot 1(4 \cdot 1)$; that of fibrosis (V-Fib) was $0.3(0.9)$ (range -2 to +2 ), evolving (nonsignificant (NS)) from $1.3(0.9)$ to $1.7(0.8)$; and that of ductal structures with infiltrating lymphocytes (V-DIL) was $0.2(0.7)$ (range -1 to +2$)$, evolving (NS) from $0.7(0.8)$ to $0.9(0.9)$ (table 2). The figure shows representative examples of the development of the focal score. Interestingly, there was a good correlation between V-FS and V-DIL $(p<0.01)$, but not between V-FS and V-Fib, nor V-DIL and V-Fib.

\section{Discussion}

Despite a substantial variation in the changes, our belief is that labial salivary gland biopsy samples, initially with scores less than two, can become positive after an interval of more than one year in patients suspected of having primary SS. In the light of this observation, the histological criterion has been considered a prerequisite for the diagnosis by two groups of investigators. ${ }^{1216}$

Waterhouse and Doniach ${ }^{17}$ investigated the 
prevalence of focal non-suppurative inflammatory lesions of the salivary and lachrymal glands in a series of subjects at necropsy, and concluded that the high occurrence of focal sialadenitis in contrast to the rarity of clinical SS suggests non-progression of most of the foci. Sjögren's syndrome is thought to be progressive, however, ${ }^{18}$ and in keeping with this interpretation we found that lymphocytic infiltration was often greater in the second than in the first biopsy specimen.

Surprisingly, there are few studies evaluating the outcome of lymphocytic infiltration in labial salivary gland biopsy samples. Repeat lip biopsy samples were taken from 14 patients by Anderson et al. ${ }^{19}$ There was more extensive lymphoid infiltration in the second biopsy specimen in seven of the ten patients who received no treatment or received treatment with prednisone, whereas two of the four patients treated with cyclophosphamide showed an improvement histologically. Tarpley et $a^{20}$ found that the histological results in untreated patients tended to be progressive in each succeeding procedure. In another paper, ${ }^{21}$ the degree of lymphocytic infiltration was reported to increase in two and decrease in the remaining two patients with primary SS who were treated with steroids.

In this study, the focal score correlated well with the number of ductal structures with infiltrating lymphocytes (but not with fibrosis). These data do not support the view that longstanding SS results in fibrous atrophy of the exocrine glands, leaving little evidence of the original highly cellular infiltration. In contrast, Maganelli et al $^{22}$ analysed morphometrically salivary glands from patients with primary SS and from matched normal control subjects and could not find any statistically significant difference in the acinar tissue, intralobular ducts, nor fibrous tissue. Our findings also indicate that the acinar atrophy is not related to the inflammatory process, and indeed atrophic changes in labial salivary gland biopsy samples are extremely common in specimens from subjects at necropsy who have no history of connective tissue disease. ${ }^{23}$

The specificity of the focal score for SS has been considered questionable. A diagnosis on these grounds is far from clear cut. Lymphocytic infiltration of exocrine glands often occurs in patients with various diseases, such as $R A,{ }^{14}$ myasthenia gravis, ${ }^{24}$ and sialothiasis. ${ }^{25}$ Lindahl and Hedfors ${ }^{26}$ found foci in labial salivary gland biopsy samples from 15 of 80 patients with connective tissue disease, but no symptoms of sicca. None of these 15 patients showed any sign of decreased lachrymal or salivary gland function after a four year follow up period. Ductal structures with infiltrating lymphocytes may be more characteristic of primary SS than the focal score. ${ }^{27}$ We suggest that ductal infiltration would be a useful adjunct for the diagnosis of SS in conjunction with the focal score.

A physiopathological sequence where lymphocytic infiltration precedes ductal proliferation is generally assumed. The primary event could be a perturbation of the ductal epithelial function, followed by a lymphocytic response, as shown by repeated biopsies in HTLV-1 tax trangenic mice. ${ }^{\angle 8}$ The latter interpretation is consistent with the virally induced mobilisation of nuclear autoantigens described by Baboonian et al, ${ }^{29}$ and the detection of these autoantigens in the cytoplasm and on the membrane of conjunctival cells from patients with primary SS. ${ }^{30}$

The authors are most grateful to Roger Casburn-Budd for editorial assistance. Thanks are also due to Annie Paul.

1 Moutsopoulos H M, Talal N. New developments in Sjögren's syndrome. Curr Opin Rheumatol 1989; 1 322-8.

2 Youinou P, Moutsopoulos H M, Pennec Y L. Clinical features of Sjögren's syndrome. Curr Opin Rheumatol 1990; 2: 287-93.

3 Moutsopoulos H M, Youinou P. New developments in primary Sjögren's syndrome. Curr Opin Rheumatol 1991; 3: 815-22.

4 Vitali C, Bombardieri S. Diagnostic criteria for Sjögren's syndrome: the state of the art. Clin Exp Rheumatol 1990; 8 (suppl 5): 13-6.

5 Mason D K, Harden R M, Boyle J A, Jasani M K, Williamson J, Buchanan W W. Salivary flow rates and iodine uptake trapping capacity in patients with Sjögren's syndrome. Ann Rheum Dis 1967; 26: 311-5.

6 Jezequel N, Depasse F, Jouquan J, et al. Salivary lactoferrin in primary Sjögren's syndrome. Clin Exp Rheumatol 1989; 7: 123-5.

7 Schall G L, Anderson L G, Woif R O, et al. Xerostomia in Sjögren's syndrome: evaluation by sequential salivary scintigraphy. $\mathcal{F} A M A 1971$; 216: 2109-16.

8 Kawamura H, Taniguchi N, Itoh K, Kano S. Salivary gland echography in patients with Sjögren's syndrome. Arthritis Rheum 1990; 33: 505-10.

9 Miyacki K, Naito M, Maeno Y, et al. Sialographic study in patients with and without antibodies to Sjögren's syndrome A (Ro). $\mathcal{F}$ Rheumatol 1983; 10: 387-94.

10 Vitali C, Tavani A, Simi U, et al. Parotid sialography and minor salivary gland biopsy in the diagnosis of Sjögren's syndrome: a comparative study of 84 patients. F Rheumatol 1988; 15: 262-7.

11 Daniels T E. Labial salivary gland biopsy in Sjögren's syndrome: assessment as a diagnostic criterion in 362 suspected cases. Arthritis Rheum 1984; 27 : 147-56.

12 Skopouli F N, Drosos A A, Papaioannou T, Moutsopoulos H M. Preliminary criteria for Sjögren's syndrome. Scand $\mathcal{F}$ Rheumatol Suppl 1986; 61: 22-5

13 Arnett F C, Edworthy S M, Bloch D A, et al. The American Rheumatism Association 1987 revised criteria for the classification of rheumatoid arthritis. Arthritis Rheum 1988; 31: 315-24.

14 Andonopoulos A P, Drosos A A, Skopouli F N Acriditis N C, Moutsopoulos H M. Secondary Sjögren's syndrome in rheumatoid arthritis. f Rheumatol 1987; 14: 1908-2103.

15 Greenspan J S, Daniels T E, Talal N, Sylvester R A. The histopathology of Sjögren's syndrome in labial salivary gland biopsies. Oral Surg 1974; 37: 217-29.

16 Fox R I, Robinson C A, Curd J G, Kozin F, Hoxell F V. Sjögren's syndrome: proposed criteria for classification. Arthritis Rheum 1986; 29: 577-85.

17 Waterhouse J P, Doniach I. Post-mortem prevalence of focal lymphocytic adenitis of the submandibular salivary gland. Fournal of Pathology and Bacteriology 1966; 91: 53-64.

18 Whaley K, Williamson J ?, Chisholm D, Webb J, Mason D, Buchanan W W. Sjögren's syndrome. I. Sicca components. $Q \mathcal{F}$ Med 1973; 42: 279-304.

19 Anderson L G, Cummings N A, Asofsky R, et al. Salivary gland immunoglobulin and rheumatoid factor synthesis in Sjögren's syndrome: natural history and response to treatment. $A m \mathcal{F}$ Med 1972; 53: 456-63.

20 Tarpley T M Jr, Anderson L G, White C L. Minor salivary gland involvement in Siögren's syndrome. Oral Surg 1974; 37: 64-73.

21 Takeda $Y$. Histopathological studies of the labial salivary glands in patients with Sjögren's syndrome. Part I: light microscopic study. Bull Tokyo Med Dent Univ 1980; 27: 9-25. 
22 Manganelli P, Salaffi F, Nervetti A, Raffaini N, Ollivetti G. Morphometric study of salivary glands in primary Sjögren's syndrome. Clin Exp Rheumatol 1989; 7: 273-6.

23 Scott J. Qualitative and quantitative observations on the histology of human labial salivary glands obtained post mortem. $\mathcal{F}$ Biol Buccale 1980; 8: 187-200.

24 Lindahl G, Lefvert A K, Hedfors E. Periductal lymphocytic infiltrates in salivary glands of myasthenia gravis patients lacking Sjögren's syndrome. Clin Exp Immunol 1986; 66: 95-102.

25 Segerberg-Honttinen $M$. Focus score in sialolithiasis. Scand $\mathcal{f}$ Rheumatol 1988; 17: 87-9.

26 Lindahl G, Hedfors E. Lymphocytic infiltrates and epithelial HLA-DR expression in lip salivary glands in connective tissue disease patients lacking sicca: a prospective study. $\mathrm{Br} \mathcal{F}$ Rheumatol 1989; 28: 293-8.
27 Pennec Y L, Leroy J P, Jouquan J, Lelong A, Katsikis P, Youinou P. Comparison of labial and sublingual biopsies in the diagnosis of Sjögren's syndrome. Ann Rheum Dis 1990; 49: 37-9.

28 Green J E, Hinrichs S H, Vogel J, Jay G. Exocrinopathy resembling Sjögren's syndrome in HTLV-1 tax transgenic mice. Nature 1989; 341: 72-4.

29 Baboonian C, Venables P J W, Booth J, Williams D G, Roffe L M, Maini $R$ N. Virus infection induces redistribution and membrane localization of the nuclear antigen La (SSB): a possible mechanism for autoimmunity. Clin Exp Immunol 1989; 78: 454-9.

30 Yannopoulos D I, Roncin S, Lamour A, Pennec Y L Moutsopoulos H M, Youinou P. Conjunctival epithelial cells from patients with Sjögren's syndrome express inappropriately major histocompatibility complex molecules, $\mathrm{La}$ (SSB) antigen and heat-shock proteins. $\mathcal{F}$ Clin Immunol. In press. 